\title{
PARTISIPASI MASYARAKAT PADA TAHAP PELAKSANAAN PROGRAM REHABILITASI LAHAN KRITIS
}

\section{PUBLIC PARTICIPATION ON IMPLEMENTATION STEP OF CRITICAL LAND REHABILITATION PROGRAM}

\author{
Dewa Oka Suparwata ${ }^{1}$, Muhammad Arsyad ${ }^{2}$, Marini Susanti Hamidun ${ }^{3}$ \\ ${ }^{1}$ Program Studi Sistem-Sistem Pertanian, \\ Program Pascasarjana Universitas Hasanuddin, Makassar \\ ${ }^{2}$ Fakultas Pertanian Universitas Hasanuddin, Makassar \\ ${ }^{3}$ Fakultas MIPA Universitas Negeri Gorontalo, Gorontalo
}

\author{
Alamat Korespondensi: \\ Dewa Oka Suparwata \\ Program Studi Sistem-Sistem Pertanian \\ Program Pascasarjana Universitas Hasanuddin \\ Makassar, 90245 \\ HP: 085298124985 \\ Email :dewaoka89_umg@yahoo.com
}




\begin{abstract}
ABSTRAK
Partsipasi masyarakat dalam rehabilitasi lahan kritis merupakan keterlibatan dan keikutsertaan masyarakat dalam segala kegiatan/program yang dicanangkan dimulai dari perencanaan program, realisasi, pemantauan dan pendampingan hingga evaluasi program. Penelitian ini bertujuan mengidentifikasi faktor internal dan ekternal yang terkait dengan tingkat partisipasi masyarakat dan mengidentifikasi tingkat partisipasi masyarakat dalam tahap pelaksanaan pada kegiatan rehabilitasi lahan kritis di DAS Randangan. Penelitian ini dilaksanakan di DAS Randangan, Kabupaten Pohuwato, Provinsi Gorontalo, dari Bulan September-November 2015. Penelitian ini menggunakan pendekatan survei dan ditetapkan secara purposif. Populasi berjumlah 150 orang dengan besar sampel sebanyak 60 orang yang ditetapkan dengan cara systematic random sampling. Data dianalisis atas analisis faktor internal dan eksternal dan tingkat partisipasi masyarakat. Hasil penelitian menunjukkan bahwa faktor-faktor yang terkait dengan rehabilitasi lahan kritis meliputi faktor internal: tingkat pendidikan dan luas lahan, adapun faktor eksternal, yakni peran pendamping, dan tingkat partisipasi masyarakat pada Rehabilitasi Lahan Kritis di DAS Randangan, Kabupaten Pohuwato pada tahap pelaksanaan tergolong sedang.
\end{abstract}

Kata Kunci: partisipasi, rehabilitasi, lahan kritis

\title{
ABSTRACT
}

Public participation on rehabilitation of critical land was the involvement and participation of the public in all the activities/programs that proclaimed starts from program planning, realization, monitoring and mentoring to evaluate the program. The research is aimed: to identify the internal and external factors that associated to the level of public participation and identify the public participation level in the stage of implementation on activity of critical land rehabilitation of Randangan watershed. This study was conducted on Randangan watershed Pohuwato Regency, Gorontalo Province from September to November 2015 used survey approach and purposively determined. There were 60 samples from 150 populations collected through systematic random sampling. The data were analyzed with internal and external factors and the level of public participation. The result indicates that: factors that related to the critical land rehabilitation covers internal factors i.e. age, education and land's width, while the external factors are the role of companion and the level of public participation on critical land rehabilitation on Randangan watershed in Pohuwato Regency on the stage of implementation is moderate.

Keywords: Participation, Rehabilitation, Critical Land 


\section{PENDAHULUAN}

Konservasi sumberdaya alam (SDA) di Indonesia menjadi tantangan besar dan tugas utama seluruh elemen baik pemerintah dan masyarakat. Pemanfaatan hasil-hasil hutan yang berlebihan berdampak pada semakin memperkeruh kerusakan lingkungan. Pemanfaatan lahan-lahan pertanian tanpa konservasi banyak memberikan dampak negatif terhadap laju degradasi lahan pada wilayah DAS. Salah satunyanya adalah DAS Randangan.

DAS Randangan memiliki luas wilayah yaitu 268.078 Ha (BP-DAS Bone Bolango, 2013). Kondisi DAS Randangan yang semakin kritis diakibatkan oleh erosi dan Aliran Permukaan (AP). Hasil penelitian Wolok et al (2014), melaporkan besarnya potensi limpasan yang terjadi pada DAS Marisa yaitu sebesar 197,779 mm tahun ${ }^{-1}$. Besarnya potensi laju erosi dan sedimentasi yang terjadi di DAS Marisa yaitu sebesar 169,364 ton ha-1 tahun $^{-1}$ atau sebesar 14,114 mm tahun ${ }^{-1}$ dan potensi sedimentasi sebesar 125,299 ton tahun ${ }^{-1}$. Proses AP dan erosi menyebabkan lahan menjadi kritis. BP-DAS Bone Bolango (2009), melaporkan luas lahan kritis untuk wilayah DAS Randangan mencapai $91.494 \mathrm{Ha}$, terdiri dari $18.832 \mathrm{Ha}$ di luar kawasan hutan, dan 72.662 Ha berada di dalam kawasan hutan. Hal ini menandakan bahwa tingginya degradasi lahan dan erosi tanah yang terjadi pada wilayah DAS Randangan.

Upaya yang dilakukan untuk menstabilkan kembali keadaan DAS ialah dengan kegiatan rehabilitasi hutan dan lahan kritis. Peraturan Presiden Republik Indonesia Tahun 2007, tentang Gerakan Nasional Rehabilitasi Hutan dan Lahan (GNRHL) menjelaskan kegiatan tersebut sebagai upaya untuk memulihkan, mempertahankan dan meningkatkan fungsi hutan dan lahan sehingga daya dukung, produktivitas dan peranannya dalam mendukung sistem penyangga kehidupan tetap terjaga. Kegiatan rehabilitasi salah satunya melalui kegiatan penghijauan. Penghijauan meliputi kegiatan persemaian/pembibitan, penanaman, pemeliharaan tanaman, dan pengamanan (Peraturan Pemerintah Nomor 76 Tahun 2008 tentang Rehabiltasi dan Reklamasi Hutan).

Kegiatan rehabilitasi lahan kritis (RLK) di Gorontalo menjadi pertanyaan besar dalam realisasi program. Pasalnya dari tahun ke tahun semakin bertambahnya lahan-lahan pertanian yang kritis. Target rehabilitasi lahan kritis tidak berhasil maksimal seperti yang diharapkan. Apalagi masyarakat yang tidak menerapkan teknik konservasi dan memiliki keterbatasan modal dan pendidikan dalam melakukan proses budidaya tanaman.

Menilai keberhasilan rehabilitasi lahan kritis dapat dilihat dan ditentukan dari tingkat partisipasi masyarakat. Partsipasi masyarakat dalam rehabilitasi lahan kritis merupakan keterlibatan dan keikutsertaan masyarakat dalam segala kegiatan/program yang dicanangkan 
dimulai dari perencanaan program, realisasi, pemantauan dan pendampingan hingga evaluasi program. Pada tahap pelaksanaan merupakan kegiatan yang meliputi: persiapan lahan (pengolahan tanah, pembersihan lahan), pembuatan bibit (persemaian benih, pemeliharaan bibit), penanaman dan pemeliharaan bibit, memberikan sumbangan materi dan pembuatan saluran irigasi. Dilaporakan oleh Siburian (2009), yang mengkaji pasrtisipasi masyarakat di Kawasan Hutan Lindung Pusuk Buhit Kabupaten Samosir memperoleh hasil kajian bahwa tingkat partisipasi masyarakat dalam GNRHL dalam kategori sedang. Mengkaji partisipasi masyarakat dipengaruhi oleh berbagai faktor. Faktor tersebut merupakan faktor internal dan eksternal masyarakat. Faktor internal seperti tingkat pendidikan dan luas lahan. Sedangkan faktor eksternal seperti peran pendamping.

Berdasarkan hal di atas maka tujuan dari penelitian ini adalah: Mengidentifikasi tingkat partisipasi masyarakat dalam tahap pelaksanaan pada kegiatan rehabilitasi lahan kritis di DAS Randangan.

\section{BAHAN DAN METODE}

\section{Lokasi dan Rancangan Penelitian}

Penelitian ini dilakukan di DAS Randangan, Kabupaten Pohuwato, Provinsi Gorontalo, pada Bulan September-November 2015, yang dipilih secara sengaja (purposive). Menggunakan pendekatan survei. Populasi adalah kelompok tani perehabilitasi lahan kritis, sebesar 150 orang, dengan besar sampel 60 responden, ditetapkan dengan secara systamatic random sampling.

\section{Metode Pengumpulan Data}

Jenis data dalam penelitian ini dikategorikan menjadi 2 macam, yaitu data yang bersifat sekunder dan primer. Data sekunder diperoleh data pengumpulan data pada Dinas Kehutanan, data Desa, BP-DAS, dan BPS. Data primer diperoleh dari hasil wawancara di lapangan. Teknik pengumpulan data melalui wawancara tidak langsung dengan pemberian kuesioner, observasi dan dokumenter.

\section{Analisis Data}

Analisis data terdiri dari: (1) Analisis faktor yang terkait dengan tingkat partisipasi masyarakat dengan menghitung besarnya persentase pada setiap faktor dari pengamatan lapangan, (2) Analisis tingkat partisipasi masyarakat menggunakan analisis skala. Skala dimaksud adalah dengan menentukan interval kelas pada masing-masing tingkatan partisipasi (rendah, sedang, tinggi), ditentukan menggunakan rumus Nasir (2013), yaitu sebagai berikut : 


$$
\begin{aligned}
k=\frac{R}{I} \quad \text { Dimana }: \mathrm{k} & =\text { interval kelas } \\
\mathrm{I} & =\text { jumlah interval kelas } \\
\mathrm{R} & =\text { range }
\end{aligned}
$$

Data diolah dengan bantuan komputer menggunakan Microsoft Office Exel.

\section{HASIL}

Desain terbaik dalam mengembalikan kelestarian dan keseimbangan alam adalah melakukan rehabilitasi lahan kritis, dengan penanaman pohon kembali. Dengan demikian pentingnya peran serta (partisipasi) masyarakat dalam ikut merehabilitasi lahan kritis dan menjaga ekosistem DAS. Kajian terhadap partisipasi masyarakat sangat dipengaruhi oleh faktor-faktor terkait yang berhubungan dengan individu masyarakat (faktor internal dan eksternal).

\section{Tingkat Pendidikan}

Hasil penelitian karakteristik responden menurut tingkat pendidikan (Tabel 1) menunjukkan bahwa karakteristik responden menurut tingkat pendidikan terbanyak berada pada tingkatan pendidikan sekolah dasar (SD) sebesar 43,3\%, dan terendah pada jenjang akademi dan perguruan tinggi sebesar $1,7 \%$.

\section{Luas Lahan}

Luas lahan yang dimaksud adalah luas lahan yang diolah oleh petani pada kegiatan rehabilitasi lahan kritis, baik milik sendiri, garap ataupun sewa. Hasil (Tabel 2), menunjukkan bahwa luas lahan yang dimiliki petani dalam kegiatan rehabilitasi lahan kritis berkisar antara 0,5-1 ha, yakni sebesar 70\%, kemudian kategori luasan $>1$ ha sebesar 20\%, dan terkecil adalah luasan $<0,5$ ha sebesar $10 \%$.

\section{Peran Pendampingan}

Hasil penelitian (Tabel 3) menunjukkan bahwa 80\% petani mengatakan ada pendampingan dari pihak pemerintah, dan 20,0\% petani mengatakan tidak ada pendampingan.

\section{Tingkat Partisipasi Masyarakat pada Tahap Pelaksanaan Program RLK}

Partisipasi masyarakat tahap pelaksanaan pada rehabilitasi lahan kritis meliputi beberapa bentuk kegiatan seperti: persiapan lahan (pengolahan tanah, pembersihan lahan), pembuatan bibit (persemaian benih, pemeliharaan bibit), penanaman dan pemeliharaan bibit, memberikan sumbangan materi dan pembuatan saluran irigasi. Hasil penelitian (Tabel 4) menunjukkan pada tahap pelaksanaan RLK di DAS Randangan tingkat partisipasi masyarakat tergolong sedang $(63,3 \%)$. 


\section{PEMBAHASAN}

Penelitian menunjukkan bahwa tingkat pendidikan masyarakat tergolong masih rendah. Namun, masyarakat telah menyadari betapa pentingnya untuk bersekolah meskipun hanya sampai pada tingkatan sekolah dasar (SD) saja. Rendahnya tingkat pendidikan berkorelasi pada rendahnya tingkat partisipasi masyarakat dalam melaksanakan program rehabilitasi lahan yang direncanakan pemerintah. Jariyah (2014), menguatkan bahwa tingkat pendidikan sangat berpengaruh terhadap keberhasilan pelaksanaan rehabilitasi lahan dan konservasi tanah, walaupun hal itu tidak menjamin bahwa pendidikan tinggi mempunyai tingkat kesadaran yang tinggi dalam menjalankan konservasi tanah dan air.

Luas lahan sangat mempengaruhi partisipasi masyarakat, seperti dijelaskan oleh Saragih dalam Fauziah (2015), menyatakan bahwa ukuran luas lahan berhubungan dengan tingkat adopsi petani, semakin luas lahan petani semakin cepat mengadopsi karena adanya kemampuan ekonomi yang lebih baik. Dengan demikian akan berdampak pada berhasilnya program rehabilitasi lahan kritis tersebut.

Temuan penelitian ini menjelaskan besarnya kontribusi peran pendamping dari pemerintah untuk kegiatan RLK. Seperti dikemukakan oleh Aisyah (2013), bahwa peran pemerintah dan masyarakat sangat dibutuhkan dalam memelihara kelestarian kawasan sehingga diharapkan akan memberi kontribusi bagi penyangga hidup masyarakat dan perekonomian nasional.

Penelitian menunjukkan tingakt partisipasi masyarakat tahap pelaksanaan tergolong sedang. Ini menandakan bahwa tidak semua tahapan kegiatan dilakukan oleh masyarakat. Hal ini sejalan dengan hasil penelitian oleh Pudjianto (2009), bahwa tingkat partisipasi masyarakat pada tahap pelaksanaan secara umum tergolong sedang $(46,8 \%)$. Hasil penelitian oleh Azis (2006), bahwa tingkat partisipasi sebagian besar peserta GN-RHL di empat desa penelitian dalam kegiatan tahap pelaksanaan program tergolong tinggi (62,50\%). Selanjutnya dilaporkan oleh Dipokusumo (2011), bahwa dalam implementasi sebagian besar berada pada posisi aktif (64,5\%). Ditambahkan oleh Dewi (2013), bahwa tingkat partisipasi masyarakat pada tahap pelaksanaan berada pada level tertinggi dibandingkan tingkat partisipasi masyarakat pada tahap perencanaan dan evaluasi.

Strategi pelestarian yang melibatkan masyarakat lokal dipandang lebih efektif dibandingkan dengan pelestarian satu arah yang hanya melibatkan pemerintah. Dengan meningkatkan kesadaran masyarakat akan pentingnya fungsi pelestarian dalam suatu kawasan, akan dapat memelihara fungsi keseimbangan ekosistem dan fungsi ekonomi 
kawasan tersebut bagi masyarakat setempat, sehingga dengan adanya keseimbangan ekosistem lingkungan tersebut diharapkan tercapai optimalisasi dan keberlanjutan pengelolaan wilayah tersebut (Erwiantono, 2006).

Banyak dijumpai kasus di lapangan bahwa partisipasi masyarakat tidak bisa secara serta merta muncul dan menjadi pendukung keberhasilan kegiatan. Beberapa asumsi umum yang harus ada agar partisipasi berjalan dengan baik sering tidak dipenuhi. Diantara asumsi tersebut bahwa masyarakat lokal memiliki kemampuan dan kemauan untuk mengelola SD hutan secara lestari. Kenyataan di lapangan menunjukkan bahwa sebagian besar masyarakat yang berada di sekitar hutan kurang atau bahkan tidak memiliki keterampilan tersebut (Siswoko, 2009). Dengan demikian pada tahap pelaksanaan program ini, sebagian besar peserta terlibat pada semua kegiatan meskipun tidak seragam antara satu desa dengan desa yang lain (Azis, 2006).

\section{KESIMPULAN DAN SARAN}

Faktor-faktor yang terkait dengan rehabilitasi lahan kritis meliputi faktor internal: tingkat pendidikan dan luas lahan, adapun faktor eksternal, yakni peran pendamping, dan tingkat partisipasi masyarakat pada tahap pelaksanaan kegiatan rehabilitasi lahan kritis di DAS Randangan Kabupaten Pohuwato tergolong sedang. Pada pelaksanaan program hendaknya pemerintah lebih mengakomodir keinginan masyarakat sehingga terdapat kebebasan/keleluasaan masyarakat untuk dapat menentukan sendiri pola rehabilitasi yang dïnginkan, dan tidak secara terpusat ditetapkan oleh pemerintah ke bawah (Top down), tetapi berdasarkan keinginan masyarakat yang ditujukan ke pemerintah (Bottom up). Disamping itu juga pemerintah lebih aktif untuk melakukan pendampingan kepada masyarakat perehabilitasi lahan kritis.

\section{DAFTAR PUSTAKA}

Aisyah S. (2013). Peningkatan Peran Pemerintah dan Masyarakat sebagai Upaya Menjaga Ekosistem dan Konservasi Lingkungan di Dieng Plateau. Jurnal Organisasi dan Manajemen UT, Vol. 9, No. 2: 135-144.

Azis N.A. (2006). Partisipasi Masyarakat dalam Program Gerakan Nasional Rehabilitasi Hutan dan Lahan (GN-RHL): Kasus di Desa Sirnagalih dan Pamalayan, Kecamatan Bayongbong serta Desa Margaluyu dan Ciburial, Kecamatan Leles, Kabupaten Garut (Skripsi). Bogor: IPB.

Balai Pengelolaan Daerah Aliran Sungai (BP-DAS) Bone Bolango. (2009). Statistik Pembangunan Balai Pengelolaan Daerah Aliran Sungai Bone Bolango. Gorontalo: Departemen Kehutanan, Direktorat Jenderal Rehabilitasi Lahan dan Perhutanan Sosial. 
Balai Pengelolaan Daerah Aliran Sungai (BP-DAS) Bone Bolango. (2013). Buku Putih Sanitasi Kabupaten Gorontalo 2013. Gorontalo: Departemen Kehutanan, Direktorat Jenderal Rehabilitasi Lahan dan Perhutanan Sosial.

Dewi A.K. (2013). Partisipasi Masyarakat dalam Rehabilitasi Lahan pada Program Kebun Bibit Rakyat (KBR) di Desa Plukaran Kecamatan Gembong Kabupaten Pati. Jurnal Pembangunan Wilayah dan Kota, Vol. 9, No. 1: 42-52.

Dipokusumo, B. 2011. Model Partisipatif Perhutanan Sosial Menuju Pengelolaan Hutan Berkelanjutan : (Kasus Pembangunan Hutan Kemasyarakatan pada Kawasan Hutan Lindung di Pulau Lombok) (Disertasi). Bogor: IPB.

Erwiantono. (2006). Kajian Tingkat Partisipasi Masyarakat dalam Pengelolaan Ekosistem Mangrove di Kawasan Teluk Pangpang-Banyuwangi. Jurnal EPP. Program Studi Sosial Ekonomi Perikanan, Fakultas Perikanan dan Ilmu Kelautan, Samarinda, Kalimantan Timur, Vol. 3, No. 1:44-50.

Fauziah K. (2015). Efektivitas Metode Penyuluhan Partisipatif terhadap Peningkatan Kapasitas Petani Kakao (Studi Kasus Petani Kakao di Desa Duampanua, Kecamatan Anreapi, Kabupaten Polman) (Tesis). Makassar: Universitas Hasanuddin.

Jariyah N.A. (2014). Partisipasi Masyarakat dalam Rehabilitasi Lahan dan Konservasi Tanah (RLKT) di Sub DAS Keduang, Kabupaten Wonogiri, Jawa Tengah. Jurnal Penelitian Sosial dan Ekonomi Kehutanan, Vol. 11, No. 3: 211-221.

Nasir M. (2013). Metode Penelitian. Cetakan Ke-8. Ghalia Indonesia. Bogor.

Pudjianto K. (2009). Partisipasi Masyarakat dalam Rehabilitasi Hutan, Lahan dan Konservasi Sumberdaya Air di Sub DAS Keduang, Daerah Hulu DAS Bengawan Solo (Tesis). Bogor: IPB.

Siburian J.V. (2009). Penentuan Jenis Tanaman dan Tingkat Partisipasi Masyarakat terhadap Gerakan Nasional Rehabilitasi Hutan dan Lahan (Studi Kasus pada Masyarakat di Kawasan Hutan Lindung Pusuk Buhit Kabupaten Samosir (Skripsi). Medan: Universitas Sumatera Utara.

Siswoko B.D. (2009). Good Forest Governance: Sebuah Keniscayaan dalam Pengelolaan Sumberdaya Hutan Lestari. Jurnal Ilmu Kehutanan UGM, Vol. III, No. 1: 1-12.

Wolok E., Suhartanto E., \& Harisuseno D. (2014). Studi Tingkat Kekritisan Lahan sebagai Dasar Arahan Rehabilitasi Hutan dan Lahan DAS Marisa di Kabupaten Pohuwato Provinsi Gorontalo. Jurnal Teknik Pengairan, Vol 5, No 1: 119-129. 


\section{LAMPIRAN:}

Tabel 1. Karakteristik Responden Menurut Tingkat Pendidikan

\begin{tabular}{lcc}
\hline Kategori Pendidikan & Jumlah (Orang) & Persentase (\%) \\
\hline Tidak tamat SD & 0 & 0,0 \\
SD & 26 & 43,3 \\
SMP/SLTP & 21 & 35,0 \\
SMA/SLTA & 12 & 20,0 \\
Akademi dan Perguruan Tinggi & 1 & 1,7 \\
Total & $\mathbf{6 0}$ & $\mathbf{1 0 0 , 0}$ \\
\hline
\end{tabular}

Sumber: Data Primer Diolah, 2015

Tabel 2. Karakteristik Responden Menurut Luas Lahan

\begin{tabular}{lcc}
\multicolumn{1}{c}{ Kategori Luas Lahan (Ha) } & Jumlah (Orang) & Persentase (\%) \\
\hline$<0,5 \mathrm{Ha}$ & 6 & 10,0 \\
$0,5-1 \mathrm{Ha}$ & 42 & 70,0 \\
$>1 \mathrm{Ha}$ & 12 & 20,0 \\
Total & $\mathbf{6 0}$ & $\mathbf{1 0 0 , 0}$ \\
\hline
\end{tabular}

Sumber: Data Primer Diolah, 2015

Tabel 3. Karakteristik Responden menurut Pendampingan yang Dilakukan pada Program RLK

\begin{tabular}{lcc}
\hline \multicolumn{1}{c}{ Kategori } & Jumlah (Orang) & Persentase (\%) \\
\hline Ada Pendampingan & 48 & 80,0 \\
Tidak Ada Pendampingan & 12 & 20,0 \\
Total & $\mathbf{6 0}$ & $\mathbf{1 0 0 , 0}$ \\
\hline
\end{tabular}

Sumber: Data Primer Diolah, 2015

Tabel 4. Hasil Penelitian Tingkat Partisipasi Masyarakat dalam Tahap Pelaksanaan pada Program RLK

\begin{tabular}{lcc}
\hline $\begin{array}{c}\text { Kategori } \\
\text { (Nilai) }\end{array}$ & $\begin{array}{c}\text { Partisipasi Masyarakat Tahap Perencanaan } \\
\text { Jumlah (Orang) }\end{array}$ & Persentase $(\boldsymbol{\%})$ \\
\hline 1-2 (Rendah) & 15 & 25,0 \\
3-4 (Sedang) & 38 & 63,3 \\
$>$ 4 (Tinggi) & 7 & 11,7 \\
Total & $\mathbf{6 0}$ & $\mathbf{1 0 0 , 0}$ \\
\hline
\end{tabular}

Sumber: Data Primer Diolah, 2015 